\title{
ANALYTICAL SOLUTION FOR SUBSURFACE GAS FLOW TO A WELL INDUCED
}

\section{BY SURFACE PRESSURE FLUCTUATIONS (U)}

May 2, 2001

Joseph Rossabi

Ronald W. Falta

\section{UNCLASSIFIED}

Does Not Contain Unclassified Nuclear Information (UCNI)

ADC and Reviewing Official

M.K. Harris, Manager Geo-Modeling Environmental Restoration Technology Section

Westinghouse Savannah River Company

Savannah River Site

Aiken, SC 29801

Prepared for the US Department of Energy under Contract DE-AC09-96SR18500

Rossabi 
This document was prepared in conjunction with work accomplished under Contract No.

DE-AC09-96SR18500 with the U.S. Department of Energy.

\section{DISCLAIMER}

This report was prepared as an account of work sponsored by an agency of the United States Government. Neither the United States Government nor any agency thereof, nor any of their employees, makes any warranty, express or implied, or assumes any legal liability or responsibility for the accuracy, completeness, or usefulness of any information, apparatus, product or process disclosed, or represents that its use would not infringe privately owned rights. Reference herein to any specific commercial product, process or service by trade name, trademark, manufacturer, or otherwise does not necessarily constitute or imply its endorsement, recommendation, or favoring by the United States Government or any agency thereof. The views and opinions of authors expressed herein do not necessarily state or reflect those of the United States Go vernment or any agency thereof.

This report has been reproduced directl y from the best available copy.

Available for sale to the public, in paper, from: U.S. Department of Commerce, National Technical Information Service, 5285 Port Roy al Road, Springfield, VA 22161, phone: (800)

553-6847, fax: (703) 605-6900, email: orders@ntis.fedworld.gov online ordering: http://www.ntis.gov/ordering.htm

Available electronically at http://www.doe.gov/bridge

Available for a processing fee to U.S. Department of Energy and its contractors, in paper, from: U.S. Department of Energy, Office of Scientific and Tech nical Information, P.O. Box 62, Oak Ridge, TN 37831-0062, phone: (865 ) 576-8401, fax: (865) 576-5728, email: reports@ adonis.osti.gov 


\section{ANALYTICAL SOLUTION FOR SUBSURFACE GAS FLOW TO A WELL INDUCED BY SURFACE PRESSURE FLUCTUATIONS}

Joseph Rossabi

Westinghouse Savannah River Company, Bldg 773-42A, Aiken, SC, 29808

Phone 803-725-5220; fax 803-725-7673; email joseph.rossabi@ srs.gov

Ronald W. Falta

Clemson University, Clemson, SC

Abstract. A simple analytical model is presented for predicting subsurface gas flow to a vadose zone well in response to atmospheric pressure fluctuations (barometric pumping). The effective radial permeability $\left(\mathrm{k}_{\mathrm{r}}\right)$ in the vicinity of the well is determined during model calibration using less than two weeks of data. By combining the flow solution with a solution for the vertical gas pressure, only atmospheric pressure data are required to predict the induced flow through a well. The ability to quantitatively predict naturally induced flow in vadose zone wells by simple and inexpensive measurements is invaluable for systems using barometric pumping for remediation.

\section{Introduction}

The prevalence and persistence of subsurface contamination by volatile organic compounds (VOCs) and the shortage of funds to remediate this contamination below regulatory action levels has led to a determined search for low cost clean up strategies. Active soil vapor extraction (ASVE) is the presumptive remedy for removing VOCs in the vadose zone and generally a very cost effective strategy until the removal rate is limited by mass transfer of residual contamination from fine grain zones to the advective flow zones accessed by ASVE. 
During the mass transfer limited phase, the cost of operating ASVE may be excessive. In addition, at small or remote sites the initial equipment and infrastructure cost for ASVE may be prohibitive. When residual contamination must still be addressed and ASVE is not cost effective, in situ natural attenuation is generally the most desirable strategy but verification of natural attenuation can be difficult and expensive. The next preferred strategy is a cleanup system that requires minimal operating expense and intervention. Employing barometric pumping, either for passive injection of nutrients to enhance bioremediation or passive extraction of contaminated soil gas, is an easily verified low cost strategy for remediation. For mass transfer limited, or remote sites, and also as an interim measure while more aggressive strategies are being selected, barometric pumping may be an appropriate cleanup choice.

Small changes in surface atmospheric pressure from diurnal patterns and weather changes cause significant, observable effects on soil gas. These effects can be exploited for subsurface characterization and remediation. The fluctuating atmospheric pressure signal at the ground surface is transmitted through the subsurface at a rate dependent on the permeability of the subsurface materials. Differences in pressure between adjacent areas results in gas flow from the area of high pressure to the area of low pressure. The perturbations in the atmospheric pressure signal are small, usually less than two percent of the total magnitude of the pressure. Because the intensity of this energy is low, the potential for harnessing it is not obvious. On closer inspection, however, the low intensity but constant energy flux can be important in natural systems and in natural systems perturbed by man. When the surface and subsurface are connected by a well, the direction and magnitude of the pressure difference between the surface and subsurface determine whether surface air will flow into the formation through the well or soil gas will flow out of the formation to the surface. Figure 1 illustrates the scenario for 
barometric pumping through a vadose zone well. In this figure, the well is screened below a substantial clayey zone. The atmospheric pressure signal will penetrate the subsurface but is delayed and damped by this low permeability material and the other materials between the screen and the ground surface. As a result, there will be a pressure difference between the subsurface at the screen depth $\left(\mathrm{P}_{\mathrm{z}}\right)$ and the surface $\left(\mathrm{P}_{\mathrm{atm}}\right)$, and flow through the well. Primarily the effective permeability of the sandy materials in the screen stratum combined with the magnitude of the pressure difference will control the magnitude of the flow. As the VOCs in the vicinity of the screened zone diffuse out of the fine grain materials into the sandy zone, they will be removed during periods of flow out of the well. Unlike ASVE systems, passive systems often operate at rates on the order of diffusion processes. As a result, the magnitude of VOC concentration in the gas phase changes slowly. If the VOC concentration in the gas is known and the flow out of the well can be predicted, the mass removal of the system can be calculated. Similarly if the nutrient uptake rate (e.g., oxygen utilization rate) is known and the flow into the subsurface can be predicted, the mass of contaminant consumed by bioremediation can be calculated.

Many researchers have devised analytical solutions to the equations describing pressure and flow in porous media with certain boundary and initial conditions. From Theis (1935) to Jacob (1940) to Cooper and Jacob (1946) and to Hantush (1964), analytical solutions to groundwater flow are still generally the first methods used to describe pumping test data. Although numerical methods can more easily solve the equations that describe particular sets of subsurface conditions, heterogeneity and lack of data often limit development of a precise and unique set of descriptive equations on which to apply these methods. In these situations an analytical solution can provide a comparable degree of accuracy and the computational advantages of exact solutions in comparison with iterative methods. When predicting the 
operation of inexpensive remediation systems, the value of simple analytical solutions is particularly poignant.

\section{Predicting Subsurface Pressure}

When the surface and subsurface are connected by a well, the direction and magnitude of the pressure difference between the surface and subsurface determine whether surface air will flow into the formation through the well or soil gas will flow out of the formation. These factors are important when using barometric pumping forces for removal of volatile contaminants from the subsurface, for injection of oxygen and nutrients to enhance bioremediation, and for understanding and interpreting soil gas measurements from wells. The solutions to the onedimensional equation describing subsurface pressure in response to surface pressure fluctuations have been published in the literature (Weeks, 1978, Shan, 1995). These solutions (often adapted from solutions derived for heat conduction) can predict the magnitude and direction of the pressure differential between the surface and subsurface, and have been used for estimating the effective vertical permeability $\left(\mathrm{k}_{\mathrm{z}}\right)$ of the intervening materials. The one-dimensional analytical solutions match field data remarkably well given the actual complexity of most subsurface systems (Weeks, 1978; Rossabi and Riha, 1994; and Shan, 1995).

From Massman et al. (1989) the equation for gas flow in the subsurface is given by:

$$
\frac{\varphi S_{g} \mu_{g}}{P_{a v g}} \frac{\partial}{\partial t} P=\nabla \cdot(\tilde{k} \nabla P)
$$


where $\varphi$ is the porosity [unitless], $S_{g}$ is the volumetric gas phase saturation [unitless], $\mu_{g}$ is the viscosity of gas $[\mathrm{kg} / \mathrm{m} \mathrm{sec}], P$ is the pressure $\left[\mathrm{kg} /\left(\mathrm{m} \mathrm{sec}^{2}\right)\right]$, and $\tilde{k}$ is the intrinsic permeability tensor including relative permeability effects $\left[\mathrm{m}^{2}\right]$. In this equation the $\tilde{k} P$ term is approximated by $\tilde{k} P_{\text {avg }}$, justified by assuming that barometric pressure fluctuations provide a small variation $(<$ $2 \%$ in most cases) in gas pressure with respect to the time-average pressure $\left(P_{\text {avg }}\right)$ of the system. This assumption is equivalent to assuming that the gas density does not vary in space (i.e., it is an incompressible fluid). This equation also neglects the gravity term in Darcy's law.

The appropriate dimensionality, geometry, and boundary conditions for the problem can now be selected and Equation 1 solved. This equation is often the starting point for solving subsurface gas pressure and flow as a result of atmospheric pressure variations. Considering only vertical flow in a homogeneous system, (1) becomes:

$\frac{\varphi S_{g} \mu_{g}}{k_{z} P_{a v g}} \frac{\partial}{\partial t} P=\frac{\partial^{2} P}{\partial z^{2}}$

One solution to equation 2 is given by:

$$
\begin{gathered}
u_{n}=\theta_{0}\left[\operatorname{erfc}\left(\frac{z}{2 \sqrt{\lambda_{z} t}}\right)+\operatorname{erfc}\left(\frac{2 d-z}{2 \sqrt{\lambda_{z} t}}\right)\right] \\
+\sum_{k=1}^{n}\left(\theta_{k}-\theta_{k-1}\right)\left\{\operatorname{erfc}\left[\frac{z}{2 \sqrt{\lambda_{z}\left(t-t_{k}\right)}}\right]+\operatorname{erfc}\left[\frac{2 d-z}{2 \sqrt{\lambda_{z}\left(t-t_{k}\right)}}\right]\right\} \\
\text { at } \mathrm{t}_{\mathrm{n}}<\mathrm{t}<\mathrm{t}_{\mathrm{n}+1},
\end{gathered}
$$


where $u=P_{z}-P_{a v g}, \theta=P_{a t m}-P_{a v g}, t$ is time, $d$ is the distance between the ground surface and the water table, $P_{z}$ and $P_{\text {atm }}$ are the pressure at depth $\mathrm{z}$ and the atmospheric pressure, respectively and $\lambda_{z}=k_{z} P_{\text {avg }} / \varphi S_{g} \mu_{g}$. The subscripts $n$ and $k$ in Equation 3 refer to the atmospheric pressure time steps

The solution used here is equivalent to the one developed by Weeks (1978) but incorporates a slightly different formulation that converges faster in most cases (Carslaw and Jaeger, 1959). Like the Weeks (1978) solution, atmospheric pressure changes are described by a series of steps but the method of images is also used to include the effect of the Nuemann boundary condition at the water table. The inputs to the model essentially include time series surface pressure data and a single value for the cumulative effective vertical permeability. The model relies on a moving sequence of historical surface pressure data to calculate current pressure values with the most recent pressure values having the greatest impact. As a result of this dependence on historical data and due to the uniform initial condition, the model requires a brief initialization period when processing a new data set.

The pressure model can be calibrated by collecting easily measured field data of surface pressure and subsurface pressure through time (Weeks, 1978; Rossabi and Riha, 1994; Shan, 1995; and Rojstacer and Tunks, 1995). Several iterations of the model are then run using different values of $\lambda_{z}$. This term is analogous to heat conduction equations with a constant diffusivity and is calculated by best fit to the field data during model calibration. Approximately two weeks of logged data has been sufficient for determining the necessary parameters for accurate future prediction using only surface pressure data (Rossabi and Riha, 1994) and $\lambda_{z}$.

An example of a model match to field data using equation 3 is given in Figure 2.The experimental method for obtaining the data and the modeling code are described in Rossabi and 
Riha (1994). Even though this system is strongly layered, the pressure response at a given depth can be modeled with the one-dimensional, homogeneous model using an average value for $\lambda_{z}$. This simulation required an initialization period lasting less than three days to establish a historical reference set used for future model predictions. Figure 2 also illustrates some typical characteristics important in discussions of atmospheric pressure and its influence on subsurface pressure. One of the most obvious features in this plot is the nearly periodic fluctuation in the pressure signal. Two cyclic signals of different frequencies and amplitudes characterize atmospheric pressure in this figure. The larger amplitude pressure cycle has a period of approximately 5 days and is caused by weather fronts passing through the experimental location. The smaller amplitude, higher frequency cycle is a result of the diurnal solar heating and cooling patterns. These two types of pressure patterns are common at all locations but vary with respect to their relative intensities depending on location, season, and other parameters. For example at some locations during stable weather, the diurnal cycle may dominate the pressure pattern with variations higher than $1000 \mathrm{~Pa}$ while weather changes vary less than $500 \mathrm{~Pa}$. At the Department of Energy's Savannah River Site (SRS), weather fronts often dominate the pressure signal during the winter while diurnal cycles are dominant during the summer.

Another key feature of this plot is the illustration of the damped and lagged response of the subsurface pressure signal to the surface pressure data. The damping and delay are a result of the resistance of the formation in transmitting the surface gas pressure signal. In this plot, the subsurface pressure at a depth of $30 \mathrm{~m}$ lags the surface pressure by approximately 12 hours. An important result of the damped and lagged response is the nearly perpetual difference in pressure between the surface and subsurface. When these two zones are connected, as by a vadose zone well, a flow of gas from the area of high pressure to the area of low pressure must ensue. This 
naturally induced flow can be used to transport mass either into or out of the subsurface. Materials that can be transported include oxygen and gaseous nutrients, volatile contaminants, moisture, etc. Energy can also be transported using the gas as a transfer fluid.

One of the dynamic parameters that is not included in analytical pressure models of this type is the variability due to changing relative permeability conditions, such as those caused by soil moisture variability. During the last 15 days shown in this figure, the model fits the data better than the first 15 days. This is probably a pitfall of using a single value of $\lambda_{z}$ for the whole data set rather than adjusting for natural changes in soil moisture due to infiltration events. Despite the slight mismatch due to natural changes in the system, the model does a good job predicting subsurface pressure. More detailed discussion of subsurface pressure modeling using one dimensional analytical solutions and the factors affecting results can be found in Weeks (1978, 1979), Rossabi and Riha (1994), Shan (1995), and Rojstacer and Tunks (1995).

\section{Derivation of Gas Flow in a Well}

Although solutions for the subsurface pressure in response to atmospheric pressure are well known, to date no analytical solutions for gas flow through a well in response to surface atmospheric pressure are available in the literature. Since the quantitative prediction of flow is one of the most important parameters (along with concentration) in engineered environmental systems, an analytical solution for flow driven by barometric pumping is valuable. The analytical solution can be simply derived with some assumptions obtained from the observation of the behavior of a barometric pumping system.

Beginning with Equation 2, we assume that the vadose zone well is fully penetrating in a relatively thin, horizontally-oriented zone of high gas permeability, and that the zone is radially 
symmetric with a single value for permeability in the screen stratum (Figure 1). Given these conditions, the partial differential equation should be posed in a cylindrical coordinate system with symmetry about the azimuth. Since we expect to have mainly radial flow near the well, the local vertical pressure gradients may be neglected in the partial differential equation (PDE) for flow to the well, and this problem becomes one-dimensional. Letting:

$$
\lambda_{r}=\frac{k_{r} P_{\text {avg }}}{\varphi S_{g} \mu_{g}}
$$

the equation for transient radial flow now becomes:

$$
\frac{1}{\lambda_{r}} \frac{\partial}{\partial t} P=\frac{\partial^{2} P}{\partial r^{2}}+\frac{1}{r} \frac{\partial P}{\partial r}
$$

The pressure difference causing flow in the well is solely a result of the damped and delayed transmission of the surface atmospheric pressure signal (a function of time) to the zone of interest in the subsurface at depth $z$. The difference between this pressure at depth $z, P_{\mathbf{z}}(t)$ and the surface pressure, $\mathrm{P}_{\mathrm{atm}}(\mathrm{t})$, generates a flow when the surface and depth $\mathrm{z}$ are connected (e.g., by a vadose zone well). The initial and boundary conditions of this system are listed below. 
At $t=0, P=P_{z}(t=0)$, where $P_{z}(t)$ is the undisturbed gas pressure at the depth of the well screen. $\mathrm{P}_{\mathbf{z}}(\mathrm{t})$ can be measured within the well, from another well screened at the same depth near the flowing well, or can be modeled from surface pressure data as discussed earlier.

Boundary conditions: As $r \rightarrow \infty, P=P_{z}(t)$; and at $r=r_{w}, P=P_{a t m}(t)$ because the well is open to the atmosphere. At this point, it is convenient to define a dimensionless radius:

$$
r^{*}=\frac{r}{r_{w}}
$$

where $r_{w}$ is the radius of the well.

Defining:

$$
\alpha=\frac{\lambda_{r}}{r_{w}{ }^{2}}=\frac{k_{r} P_{a v g}}{\varphi S_{g} \mu_{g} r_{w}{ }^{2}},
$$

the PDE for transient radial flow (Equation 5) becomes:

$$
\frac{1}{\alpha} \frac{\partial P}{\partial t}=\frac{\partial^{2} P}{\partial r^{*}}+\frac{1}{r^{*}} \frac{\partial P}{\partial r^{*}}
$$

It is convenient to define a new pressure variable in which the barometric fluctuations are subtracted out:

$$
S(r, t)=P(r, t)-P_{z}(t),
$$

where $\mathrm{S}$ is the pressure drawdown or build-up relative to ambient pressure at depth. Note that 


$$
\frac{\partial S}{\partial r}=\frac{\partial P}{\partial r} \quad \text { and } \quad \frac{\partial S}{\partial t}=\frac{\partial P}{\partial t}-\frac{\partial P_{z}}{\partial t}
$$

Including the barometric effect and assuming:

$$
\begin{aligned}
& \frac{\partial P}{\partial t} \gg>\frac{\partial P_{z}}{\partial t} \text { near the well, Equation } 8 \text { becomes: } \\
& \frac{1}{\alpha} \frac{\partial S}{\partial t}=\frac{\partial^{2} S}{\partial r^{*}}+\frac{1}{r^{*}} \frac{\partial S}{\partial r^{*}}
\end{aligned}
$$

The initial and boundary conditions are listed below.

Initial condition: At $\mathrm{t}=0, \mathrm{~S}=0$. Boundary Conditions: As $\mathrm{r}^{*} \rightarrow \infty, \mathrm{S}=0$; and at $\mathrm{r}^{*}=1$, $\mathrm{S}=\mathrm{S}_{\mathrm{wb}}(\mathrm{t})=\mathrm{P}_{\mathrm{atm}}(\mathrm{t})-\mathrm{P}_{\mathrm{z}}(\mathrm{t})$

Considering a step change in $\mathrm{S}$ at $\mathrm{t}>0$, this problem is equivalent to that of a flowing groundwater well in a nonleaky aquifer. The solution for that problem is given by Jacob and Lohman (1952), and Hantush (1964) [see also Carslaw and Jaeger (1959) for the equivalent heat conduction solution in a region bounded internally by a circular cylinder as with heat flow from buried pipes or cables] as:

$$
\mathrm{S}=\mathrm{S}_{\mathrm{wb}} \mathrm{A}\left(\tau, \mathrm{r}^{*}\right)
$$

$\mathrm{A}\left(\tau, \mathrm{r}^{*}\right)$ is called the flowing well function for non-leaky aquifers and is defined by: 


$$
A\left(\tau, r^{*}\right)=1-\frac{2}{\pi} \int_{u=0}^{\infty} e^{-\tau u^{2}} \frac{J_{0}(u) Y_{0}\left(r^{*} u\right)-Y_{0}(u) J_{0}\left(r^{*} u\right)}{J_{0}^{2}(u)+Y_{0}^{2}(u)} \frac{d u}{u} .
$$

For the gas flow problem,

$$
\tau=\alpha t=\frac{k_{r} P_{\text {avg }} t}{\varphi S_{g} \mu_{g} r_{w}{ }^{2}}
$$

To solve for the flow rate at the well, Darcy's law is used in the form:

$$
Q=-2 \pi b \frac{k_{r}}{\mu_{g}} \frac{\partial S}{\partial r^{*}} \quad \text { at } \mathrm{r}^{*}=1,
$$

where $b$ is the thickness of the screened interval or zone thickness. The derivative, $\frac{\partial S}{\partial r^{*}}$ is given by Jacob and Lohman (1952), Hantush (1964) and Carslaw and Jaeger (1959) as:

$$
\left.\frac{\partial S}{\partial r^{*}}\right|_{r^{*}=1}=\frac{-4 S_{w b}}{\pi^{2}} \int_{u=0}^{\infty} e^{-\tau u^{2}} \frac{1}{J_{0}^{2}(u)+Y_{0}^{2}(u)} \frac{d u}{u} .
$$

Combining Equations 14 and 15, the equation for flow is defined as:

$$
Q=2 \pi b \frac{k_{r}}{\mu_{g}} S_{w b} G(\tau)
$$

where $G(\tau)$ is known as the flowing well discharge function for nonleaky aquifers (Jacob and Lohman, 1952; Hantush, 1964). This function is defined as: 


$$
G(\tau)=\frac{4}{\pi^{2}} \int_{u=0}^{\infty} e^{-\tau u^{2}} \frac{1}{J_{0}^{2}(u)+Y_{0}^{2}(u)} \frac{d u}{u}
$$

From Jacob and Lohman (1952), Carslaw and Jaeger (1959), and Hantush (1964), it is known that for large $\tau, G(\tau)$ can be approximated by a simpler representation:

$$
\text { For } \quad \tau>500, \quad G(\tau) \approx \frac{2}{\ln (2.25 \tau)} \text {. }
$$

Considering typical vadose zone properties $\left(\mathrm{k}_{\mathrm{r}}=10 \mathrm{E}-12 \mathrm{~m}^{2}, \varphi=0.4, \mathrm{~S}_{\mathrm{g}}=0.10, \mathrm{r}_{\mathrm{w}}=0.0254 \mathrm{~m}\right)$, $\tau$ is greater than 500 for times larger than about 0.25 second. Therefore, the approximate solution for calculating flow from a well as a result of a step change in well gas pressure is:

$$
Q(t)=2 \pi b \frac{k_{r}}{\mu_{g}} S_{w b} \frac{2}{\ln (2.25 \tau)}
$$

For a succession of step changes in well pressure, superposition in time can be used as before. This method includes the effects of prior pressure and its influence on the current flow through the well. Equation 18 becomes:

$$
Q_{n}(t)=2 \pi b \frac{k_{r}}{\mu_{g}}\left[S_{w b(0)}\left(\frac{2}{\ln (2.25 \alpha t)}\right)+\sum_{k=1}^{n k}\left(S_{w b(k)}-S_{w b(k-1)}\right)\left(\frac{2}{\ln \left(2.25 \alpha\left(t-t_{k}\right)\right)}\right)\right] \text { (19) }
$$


for $\mathrm{t}_{\mathrm{nk}}<\mathrm{t}<\mathrm{t}_{\mathrm{nk}+1}$, where $\mathrm{S}_{\mathrm{wb}(\mathrm{k})}=\mathrm{P}_{\mathrm{atm}}\left(\mathrm{t}_{\mathrm{k}}\right)-\mathrm{P}_{\mathrm{z}}\left(\mathrm{t}_{\mathrm{k}}\right)$. This solution can be used directly with surface/subsurface differential pressure data to predict flow from a well screened in a flow zone. The code for a computer model using this solution has been developed and requires surface/subsurface differential pressure data, the thickness of the flow zone, well radius, radial permeability, volumetric moisture content, porosity, and the yearly average pressure as input. Like the subsurface pressure solution, the flow solution is calibrated using field data to calculate the best fit for a single permeability value. In this case, the value is $k_{r}$, the radial permeability of the formation. The flow solution (Equation 19) can also be coupled with the subsurface pressure solution (Equation 3). Using these two analytical solutions, flow from a vadose zone well can be predicted using only surface pressure data. The executable code for both of these models is available from the authors.

In many cases, all of the model parameters will not be available so a sensitivity analysis was performed to determine the most important variables. Tables 1 and 2 show, respectively, the input values used in the model and the results of this sensitivity analysis. From Table 2 it is clear that differential pressure and radial permeability are the most important factors in determining the flow. If differential pressure is known (either by field measurements or by using one of the analytical solutions to pressure and surface pressure data), and permeability is known, and as long as estimates of the other parameters are reasonable, the flow through the well can be predicted accurately. It is important to remember that in this derivation, the radial permeability is assumed to have a single value and is independent of changes that might result from the presence of multiple fluid phases. 


\section{Results and Discussion}

Pressure and flow measurements were made in vadose zone well CPT RAM 16 at the A/M area of the Savannah River Site in Aiken, South Carolina. Figure 3 illustrates the configuration of the instrumentation. In this setup, a pressure sensor (Vaisala model PTA 427) was connected to a port in the one-inch diameter PVC well (CPT RAM 16) before a pipe constriction where two mass flow meters (Omega FMA 5612) were attached. The flow meters were connected in opposing directions to accurately measure flow when the well was exhaling and inhaling. The analog voltage signals from the mass flow meters and the pressure transducer were routed to a data logger (Campbell Scientific model CR21X), averaged and recorded every 10 minutes.

Figure 4 shows another comparison between field measured and model predicted subsurface pressure using Equation 3 with surface pressure data. The input parameters were taken from field measurements of vadose zone well CPT RAM 16 and are listed in Table 3. The subsurface pressure match is generally good but it does not precisely track the amplitude extents of some of the pressure changes seen in the field data. This may be explained by the monitoring setup shown in Figure 3. Even though the well is not sealed, by Bernoulli's equation the pressure in the well is approximately, but not exactly, the same as the shut in well pressure because of the significant reduction in cross sectional area of the flow path caused by the mass flow meters.

Figure 5 shows a comparison between field measured and model predicted flow using the differential pressure data predicted by Equation 3 (shown in Figure 4) and Equation 19. The input parameters for this model are given in Table 4 below. It is clear from this figure that flow out of a vadose zone well can be reasonably predicted using only surface pressure data. Similar to the pressure prediction, the flow prediction is accurate but misses some of the more dynamic 
flow behavior. Equation 19 was then used with the measured differential pressure data to compare the amount of error introduced by model predicted pressure differential. Figure 6 shows a comparison between field measured and model predicted subsurface flow using Equation 19 with measured differential pressure as the input data. The other input parameters were identical to those used for the model in Figure 5 and are listed in Table 4.

The sum of squared errors (SSE) between the field measured flows and the flows predicted by modeling measured differential pressure and predicted differential pressure (based on surface pressure) were compared. The SSE from the measured differential pressure was approximately $30 \%$ smaller than the SSE from the surface pressure data set. Both of these flow models were performed without using any historical data points (only the current differential pressure for that time step). To assess the impact of including the differential pressure history in the model predictions, Equation 19 was used to predict flows using four different amounts of historical differential pressure values. For these models, the measured differential pressure data were used and the other input values were the same as those used in Figure 6. Figure 7 shows that the amount of differential pressure history included has a small effect on the flow prediction in this system. In general using more historical data points tends to moderate the flow response to an average flow value. As illustrated in Figure 7, this effect is small so it does not seem critical to include much historical data in future model runs. In this case Equation 19 may be replaced with

$$
Q_{n}(t)=2 \pi b \frac{k_{r}}{\mu_{g}} S_{w b(k)} \frac{2}{\ln \left(2.25 \alpha\left(t-t_{k}\right)\right)},
$$


where $n$ and $k$ are flow and pressure time steps respectively. The minimal effect indicates that the flow as measured at this time step (600 seconds) does not significantly impact the subsurface pressure field around the well. This small effect on the flow solution strongly contrasts with the impact of historical data points on the pressure solution of Equation 3. In this case, the pressure history is much more important and several days of data may be required to optimize the subsurface pressure prediction.

To assess the theoretical effects of using more or less historical data points, an analysis of the error between predictions using a large range of data points was performed. For this analysis the flow predicted using the maximum amount of available historical data points was assumed to be the true value for a particular time. The predicted flow value using various amounts of historical data points was then compared to the "true" value. Any difference between the two values was considered error. The errors were then treated for each data set (i.e., set using a specific quantity of historical data points) and compared. Approximately 5400 flow data (37.6 days at 10-minute intervals) were used in each comparison. Figure 8 shows the results of the comparisons. In this figure it is clear that the average error for each point is very low (less than 1 liter per minute) and the value of additional historical data points drops quickly. These results echo the findings in Figure 7.

Fewer historical data points for the flow solution may actually slightly improve fits to measured flow because the flow is dependent on the differential pressure between the surface and subsurface. If the subsurface pressure is assumed to change at a much slower rate than the surface pressure the damping effect of the historical data may not allow a rapid enough response to the dynamic surface pressure signal. Again this effect is very small as shown in Figures 7 and 8. 
Figure 9 shows the sensitivity of the model to different values of permeability. As discussed in the sensitivity analysis earlier, the flow prediction is most sensitive to this parameter. Figure 9 used the measured differential pressure data as input as well as the same input parameters listed in Table 4, varying only the radial permeability. It is clear from this figure that the model is quite sensitive to different permeability values.

These figures show that simple analytical solutions and easily measured data can be used to estimate radial gas permeability values and therefore flow through a well. The passive pumping test may be the most straightforward and least expensive way to obtain this important data in some situations. For the models shown in Figure 4 and 5, a value of radial permeability was selected to obtain the best fit to the data, and this value is consistent with other values for permeability in similar zones measured during vadose zone pumping tests conducted in the area (Looney et al., 1991). For practical uses of this model, it would probably be best to collect field flow data either by a pumping test or by measuring barometrically induced flow for a few weeks to accurately determine the radial permeability. Once the permeability is determined, the system will be calibrated for all future flow predictions. Of course the process of fitting the model to the barometric flow data is in itself an innovative method for determining the radial permeability of the formation around the well screen.

\section{Conclusions}

Using simple analytical solutions to the governing equations for pressure and flow in the subsurface, subsurface pressure and flow through a vadose zone well can be accurately modeled based on measured atmospheric pressure and subsurface properties. Each of the models can determine subsurface permeability values that are difficult to measure. Logging subsurface 
pressure or flow for relatively short durations (one to two weeks) can accomplish calibration of the subsurface pressure model or the flow model respectively. The calibration process essentially determines values for the cumulative effective vertical permeability $\left(\mathrm{k}_{\mathrm{z}}\right)$ in the pressure model case, and radial permeability $\left(\mathrm{k}_{\mathrm{r}}\right)$ in the flow model case. Once calibrated both models need only time series surface pressure data to provide accurate predictions of subsurface pressure or induced flow through a well. The flow model is most sensitive to differential pressure values, intrinsic permeability, and to a lesser extent zone thickness. It is relatively insensitive to values of porosity, average pressure, and well radius. This derivation represents the first time an analytical solution to flow through a well driven by surface pressure fluctuations has been described in the literature. By simple measurements of surface pressure, both the pressure and flow models can be used to predict the performance of a well under the influence of barometric pumping and to estimate the expected range of flow rates and variability to simplify and improve monitoring plans.

\section{Acknowledgements}

The authors would like to acknowledge the contributions and support provided by Brian D. Riha, Brian B. Looney, and the members of the Barometric Pumping Working Group. We also are grateful for the valuable comments and suggestions included in this paper from reviewers, Wei Xing Guo, Philip H. Staufer, and an anonymous reviewer. This paper was prepared by Westinghouse Savannah River Company (WSRC) for the United States Department of Energy (DOE) under Contract No. DE-AC09-96-SR18500. 


\section{$\underline{\text { References }}$}

Carslaw, H. S., and J. C. Jaeger, Conduction of Heat in Solids, Clarendon Press, Oxford, 1959.

Cooper, H. H., Jr., and C. E. Jacob, A generalized graphical method for evaluating formation constants and summarizing well field history, Trans. Amer. Geophys. Union, 27, 526$534,1946$.

Hantush, M. S., Hydraulics of wells, Adv. Hydrosci., 1, 281-432, 1964.

Jacob. C. E., On the flow of water in an elastic artesian aquifer, Trans. Amer. Geophys. Union, 2, 574-586, 1940.

Jacob. C. E. and S. W. Lohman, Nonsteady flow to a well of constant drawdown in an extensive aquifer, Trans. Amer. Geophys. Union, 33 (4), 559-569, 1952.

Looney, B. B., J. B. Pickett, and J. J. Malot, Pilot Test of a Vacuum Extraction System for Environmental Remediation of Chlorinated Solvents at the Savannah River Site (U), WSRC-RD-91-19, Westinghouse Savannah River Company, Aiken, SC 29808, 1991.

Massman, J. W., Applying groundwater flow models in vapor extraction system design, Journal of Environmental Engineering, 115 (1), 129, 1989.

Rossabi 
Rojsctacer, S., and J. P. Tunks, Field-based determination of air diffusivity using soil air and atmospheric time series, Water Resour. Res., 31(12), 3337, 1995.

Rossabi, J. and B.D. Riha, Passive control of VOCs using valved well heads: FY 1994 report (U), WSRC-TR-94-0524, Westinghouse Savannah River Company, Aiken, SC 29808, 1994.

Shan, C., Analytical solutions for determining vertical air permeability in unsaturated soils, Water Resour. Res., 31(9), 2193, 1995.

Spiegel, M. R., Schaum's Outlines Laplace Transforms, McGraw-Hill, Inc. - New York, 1965.

Theis, C. V., The relation between the lowering of the piezometric surface and the rate and duration of discharge of a well using groundwater storage, Trans. Amer. Geophys. Union, 2, 519-524,1935.

Weeks, E. P., Field determination of vertical permeability to air in the unsaturated zone, US Geological Survey Professional Paper 1051, 1978.

Weeks, E. P., Barometric fluctuations in wells tapping deep unconfined aquifers, Water Resour. Res., 15(5), 1167, 1979. 
Table 1. Description of input variables and base case values for these parameters.

\begin{tabular}{cccc}
\hline \multicolumn{4}{c}{ Model Input } \\
\hline \multicolumn{2}{c}{ Base Case Values } & Definitions & Units \\
\hline $\mathrm{k}_{\mathrm{r}}=$ & $1.00 \mathrm{E}-12$ & Radial Permeability & $\mathrm{m}^{2}$ \\
$\mu_{\mathrm{g}}=$ & $1.83 \mathrm{E}-5$ & Viscosity & $\mathrm{kg} / \mathrm{m} \mathrm{sec}$ \\
$\varphi=$ & 0.35 & Porosity & unitless \\
$\mathrm{S}_{\mathrm{g}}=$ & 0.25 & Gas Phase Saturation & unitless \\
$\mathrm{P}_{\mathrm{avg}}=$ & 100000 & Average Pressure & $\mathrm{Pa}$ \\
$\mathrm{r}_{\mathrm{w}}=$ & 0.0254 & Well radius & $\mathrm{m}$ \\
$\mathrm{b}=$ & 10 & Zone Thickness & $\mathrm{m}$ \\
$\mathrm{S}_{\mathrm{wb}}=\mathrm{P}_{\mathrm{diff}}=$ & 100 & Pressure Differential & $\mathrm{Pa}$ \\
\hline
\end{tabular}


Table 2. Sensitivity analysis of factors affecting flow through well.

\begin{tabular}{|c|c|c|c|c|c|c|c|c|}
\hline \multicolumn{9}{|c|}{ Sensitivity Analysis } \\
\hline \multicolumn{3}{|c|}{ Radial Permeability } & \multicolumn{3}{|c|}{ Pressure Differential } & \multicolumn{3}{|c|}{ Zone Thickness } \\
\hline $\mathrm{k}_{\mathrm{r}}\left(\mathrm{m}^{2}\right)$ & Q & Variance & $\mathrm{P}_{\text {diff }}$ & $\mathrm{Q}$ & Variance & $\mathrm{b}$ & Q & Variance \\
\hline & $(\mathrm{cfm})$ & $(\%)$ & (Pa) & $(\mathrm{cfm})$ & $(\%)$ & (m) & $(\mathrm{cfm})$ & $(\%)$ \\
\hline $1 \mathrm{E}-13$ & 0.015 & $88 \%$ & 50 & 0.059 & $50 \%$ & 1 & 0.012 & $90 \%$ \\
\hline $5 \mathrm{E}-13$ & 0.063 & $47 \%$ & 100 & 0.118 & $0 \%$ & 2 & 0.024 & $80 \%$ \\
\hline $1 \mathrm{E}-12$ & 0.118 & $0 \%$ & 200 & 0.237 & $100 \%$ & 5 & 0.059 & $50 \%$ \\
\hline $5 \mathrm{E}-12$ & 0.523 & $342 \%$ & 300 & 0.355 & $200 \%$ & 10 & 0.118 & $0 \%$ \\
\hline $1 \mathrm{E}-11$ & 0.997 & $742 \%$ & 400 & 0.473 & $300 \%$ & 20 & 0.237 & $100 \%$ \\
\hline $5 \mathrm{E}-11$ & 4.489 & $3693 \%$ & 500 & 0.592 & $400 \%$ & 30 & 0.355 & $200 \%$ \\
\hline \multirow[t]{2}{*}{$1 \mathrm{E}-10$} & 8.610 & $7174 \%$ & 600 & 0.710 & $500 \%$ & & & \\
\hline & & & 700 & 0.829 & $600 \%$ & & & \\
\hline
\end{tabular}

\begin{tabular}{cccccccccccc}
\hline & Porosity & \multicolumn{9}{c}{ Gas Phase Saturation } & \multicolumn{3}{c}{ Average Pressure } & \multicolumn{3}{c}{ Well Radius } \\
\hline$\varphi$ & $\mathrm{Q}$ & Var. & $\mathrm{S} \mathrm{S}_{\mathrm{g}}$ & $\mathrm{Q}$ & $\mathrm{Var}$. & $\mathrm{P}_{\mathrm{avg}}$ & $\mathrm{Q}$ & $\mathrm{Var}$. & $\mathrm{r}_{\mathrm{w}}$ & $\mathrm{Q}$ & Var. \\
& $(\mathrm{cfm})$ & $(\%)$ & & $(\mathrm{cfm})$ & $(\%)$ & $(\mathrm{kPa})$ & $(\mathrm{cfm})$ & $(\%)$ & $(\mathrm{cm})$ & $(\mathrm{cfm})$ & $(\%)$ \\
\hline 0.25 & 0.115 & $3 \%$ & 0.1 & 0.110 & $7 \%$ & 98.5 & 0.119 & $0.12 \%$ & 1.25 & 0.106 & $10 \%$ \\
0.30 & 0.117 & $1 \%$ & 0.2 & 0.116 & $2 \%$ & 99.0 & 0.118 & $0.08 \%$ & 2.54 & 0.118 & $0 \%$ \\
0.35 & 0.118 & $0 \%$ & 0.3 & 0.120 & $2 \%$ & 99.5 & 0.118 & $0.04 \%$ & 3.79 & 0.127 & $7 \%$ \\
0.40 & 0.120 & $1 \%$ & 0.4 & 0.123 & $4 \%$ & 100.0 & 0.118 & $0 \%$ & 5.08 & 0.133 & $13 \%$ \\
0.45 & 0.121 & $2 \%$ & 0.5 & 0.125 & $6 \%$ & 100.5 & 0.118 & $0.04 \%$ & & & \\
0.50 & 0.122 & $3 \%$ & 0.6 & 0.127 & $8 \%$ & 101.0 & 0.118 & $0.08 \%$ & & & \\
0.55 & 0.123 & $4 \%$ & 0.7 & 0.129 & $9 \%$ & 101.5 & 0.118 & $0.12 \%$ & & & \\
& & & 0.8 & 0.131 & $10 \%$ & 102.0 & 0.118 & $0.16 \%$ & & \\
\hline
\end{tabular}


Table 3. List of input parameters for model Barosolv.

\begin{tabular}{cc}
\hline \multicolumn{2}{c}{ Input Parameters for Model Barosolv } \\
\hline Porosity $=0.4$ & Well radius $=1.27 \mathrm{~cm}$ \\
Gas phase saturation $\left(\mathrm{S}_{\mathrm{g}}\right)=0.25$ & Depth of well $=32.2 \mathrm{~m}$ \\
& Calibrated vertical permeability \\
Average pressure $=100.4 \mathrm{kPa}$ & $\left(\mathrm{k}_{\mathrm{z}}\right)=2.4 \mathrm{E}-13 \mathrm{~m}^{2}$ \\
\hline Differential pressure data continuously logged at 10 minute intervals from 3/18/94 to \\
\\
\hline
\end{tabular}


Table 4. List of input parameters for model Baroflow.

\begin{tabular}{cc}
\hline \multicolumn{2}{c}{ Input Parameters for Model Baroflow } \\
\hline Porosity $=0.4$ & Well radius $=1.27 \mathrm{~cm}$ \\
Gas phase saturation $\left(\mathrm{S}_{\mathrm{g}}\right)=0.9$ & Permeable zone thickness $=30 \mathrm{~cm}$ \\
Average pressure $=100.4 \mathrm{kPa}$ & Calibrated radial permeability \\
& $\left(\mathrm{k}_{\mathrm{r}}\right)=40 \mathrm{E}-12 \mathrm{~m}^{2}$ \\
\hline Differential pressure data continuously logged at 10 minute intervals from 3/18/94 to \\
$4 / 25 / 94$.
\end{tabular}




\section{Subsurface Scenario}

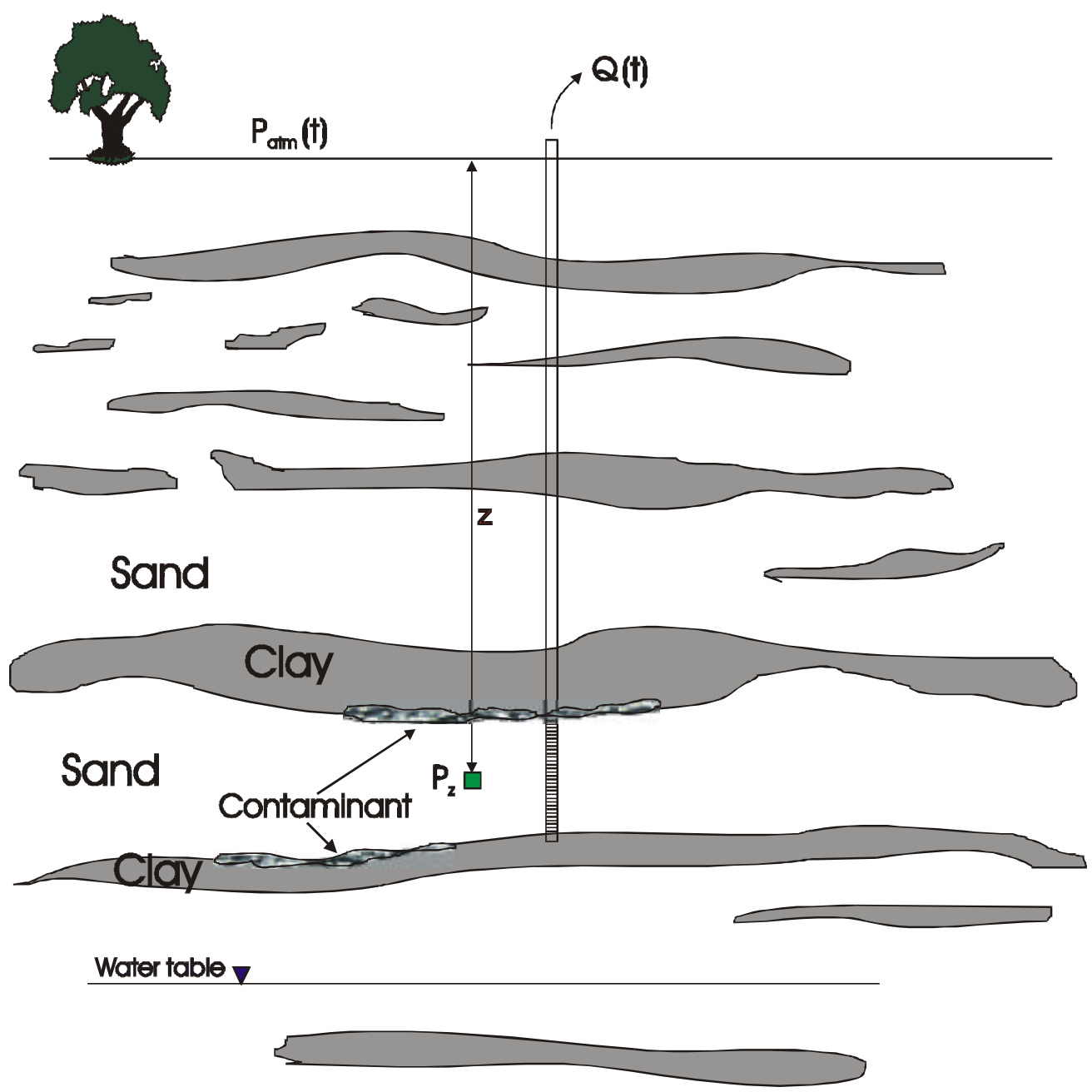

Figure 1. Scenario for analytical solution to barometrically induced flow through a well. 


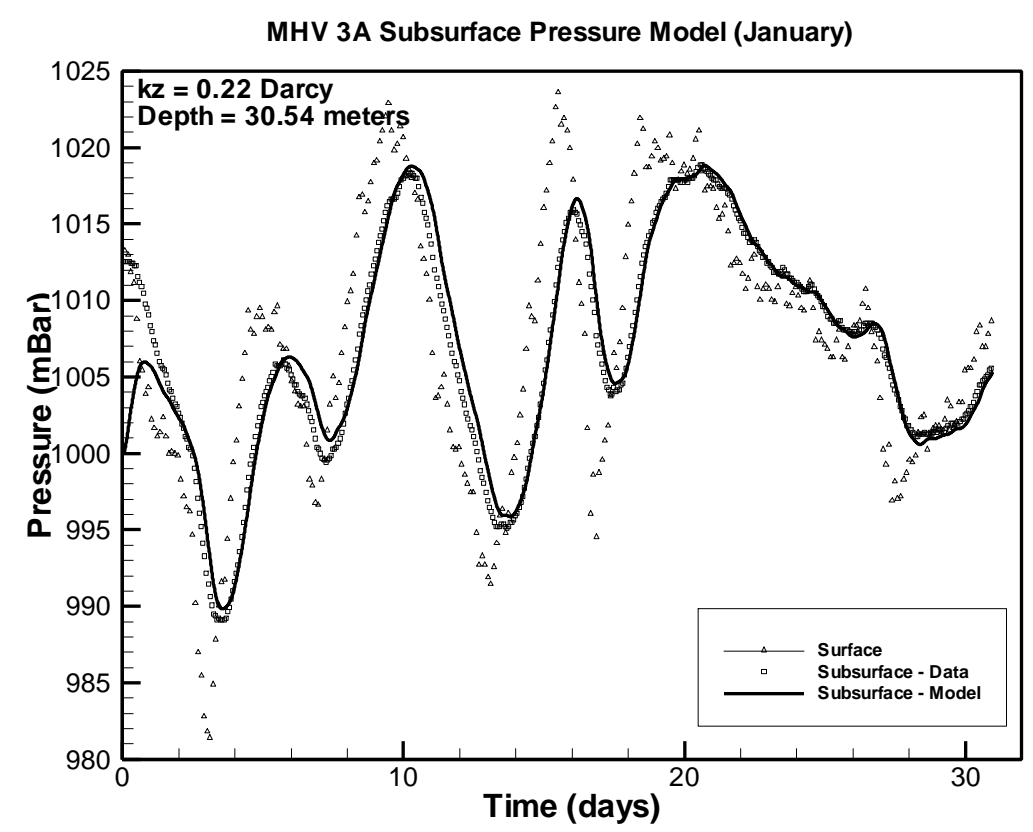

Figure 2. Subsurface pressure data and model predicted data given surface pressure. 


\section{Instrumentation For Pressure and Fow Field Experiments}

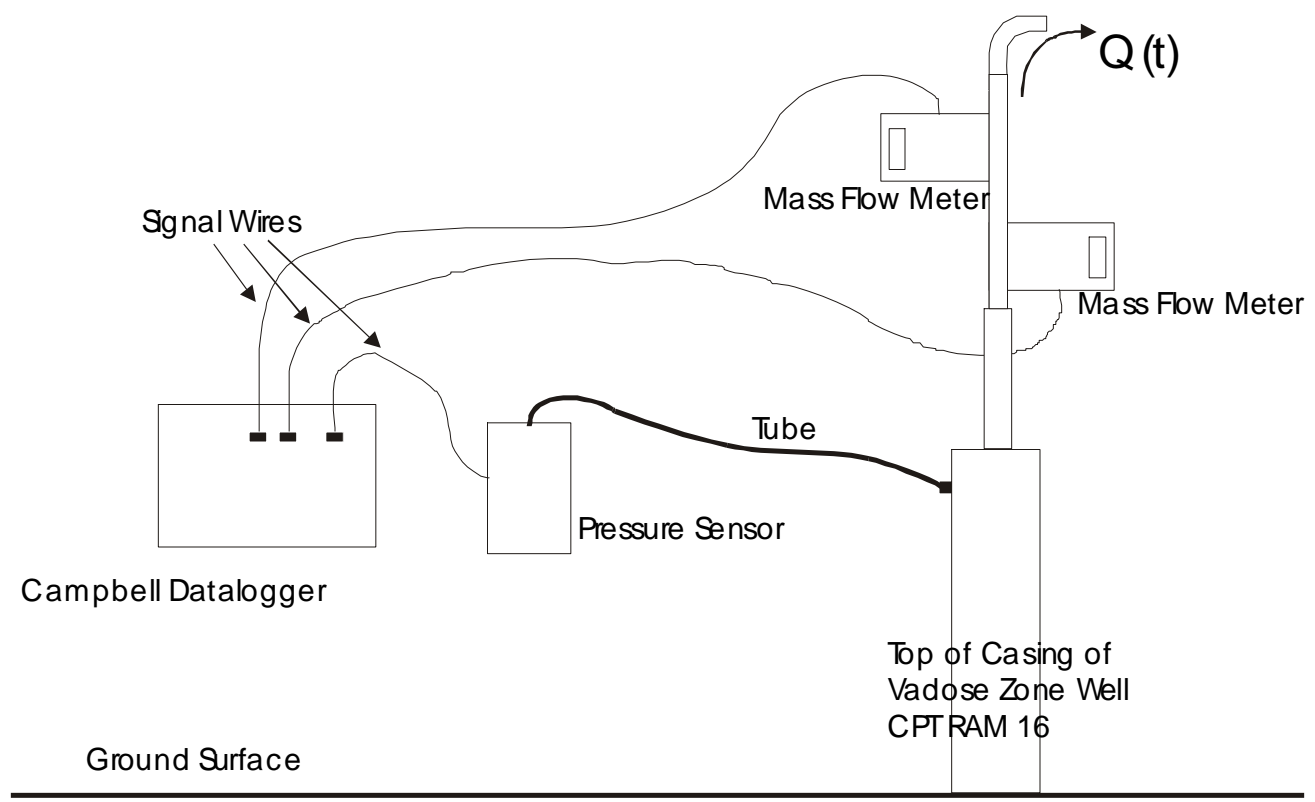

Figure 3. Monitoring equipment configuration on vadose zone well CPT RAM 16. 


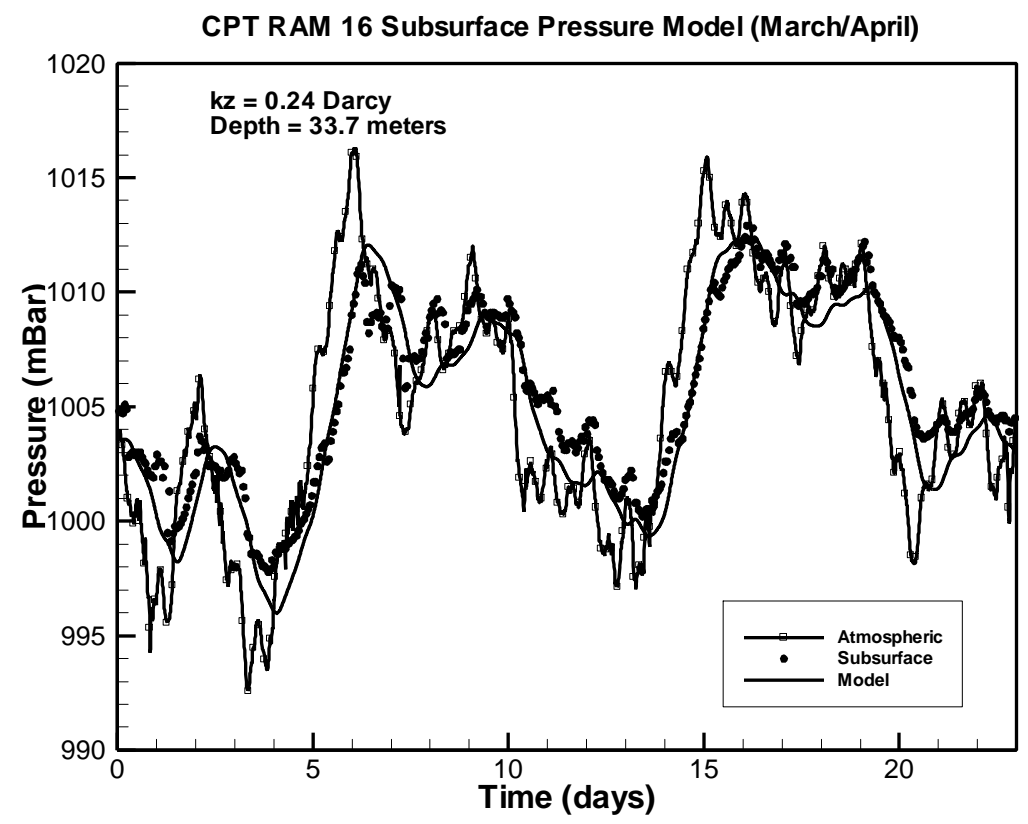

Figure 4. Comparison of field and computer modeled pressure data. 


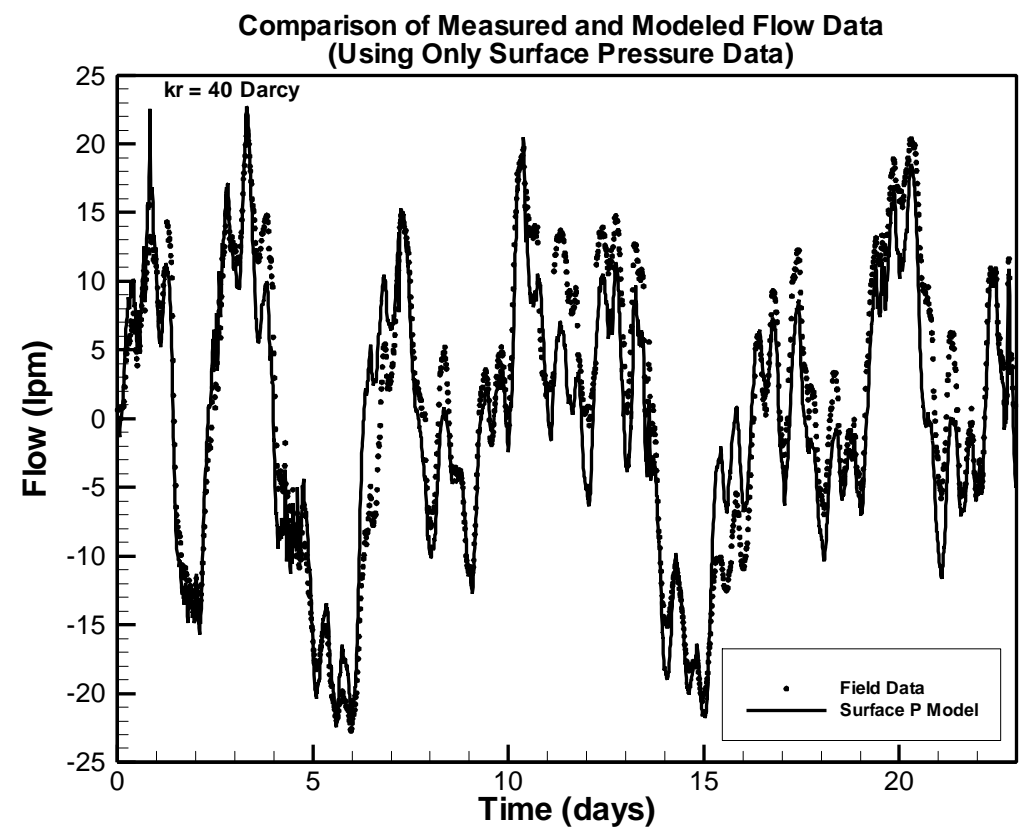

Figure 5. Comparison of field measured and computer modeled flow data using measured surface pressure as model input. 


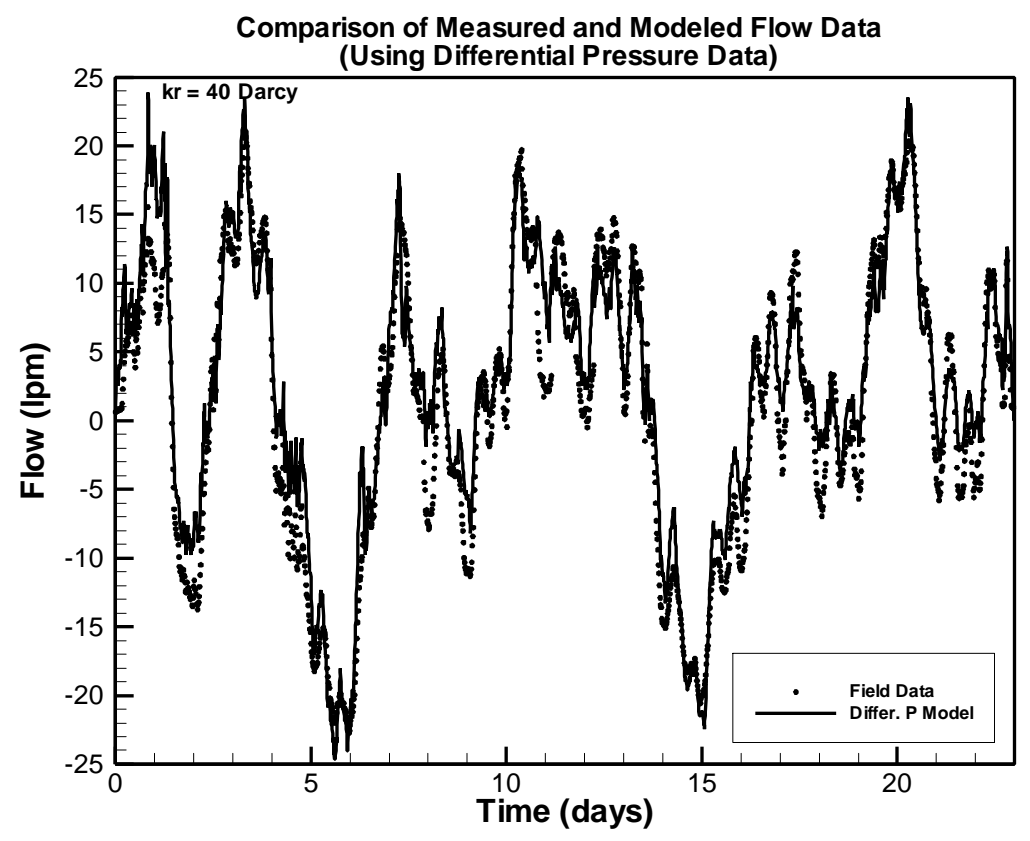

Figure 6. Comparison of field measured and computer modeled flow data using measured differential pressure as model input. 
Sensitivity of Flow Model to Number of Historical Datapoints

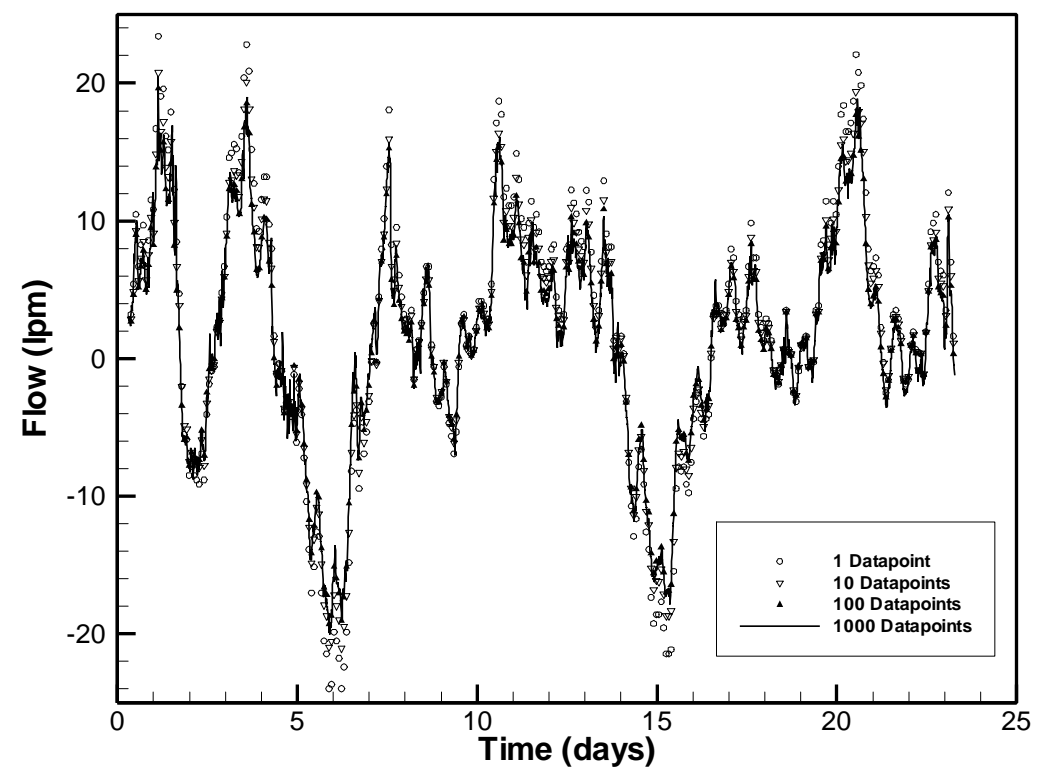

Figure 7. Model response to the number of historical data points used. 


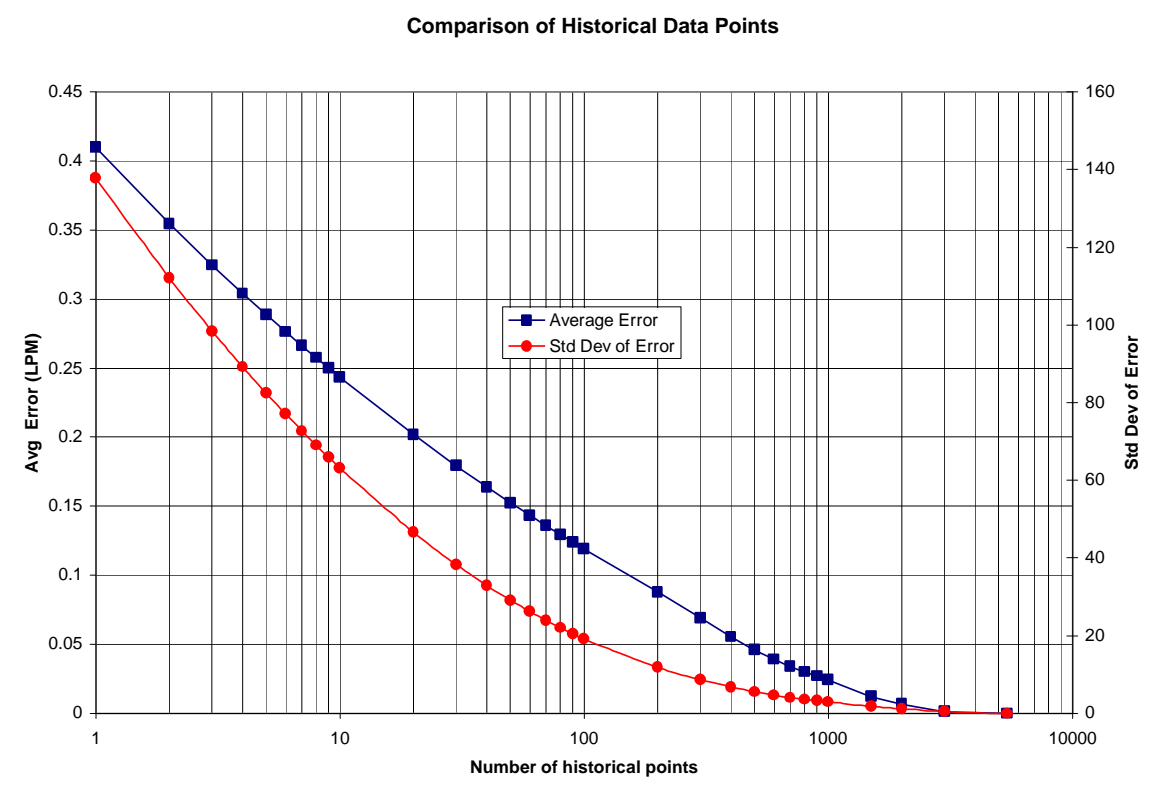

Figure 8. Error evaluation of modeling with varying numbers of historical data points. 


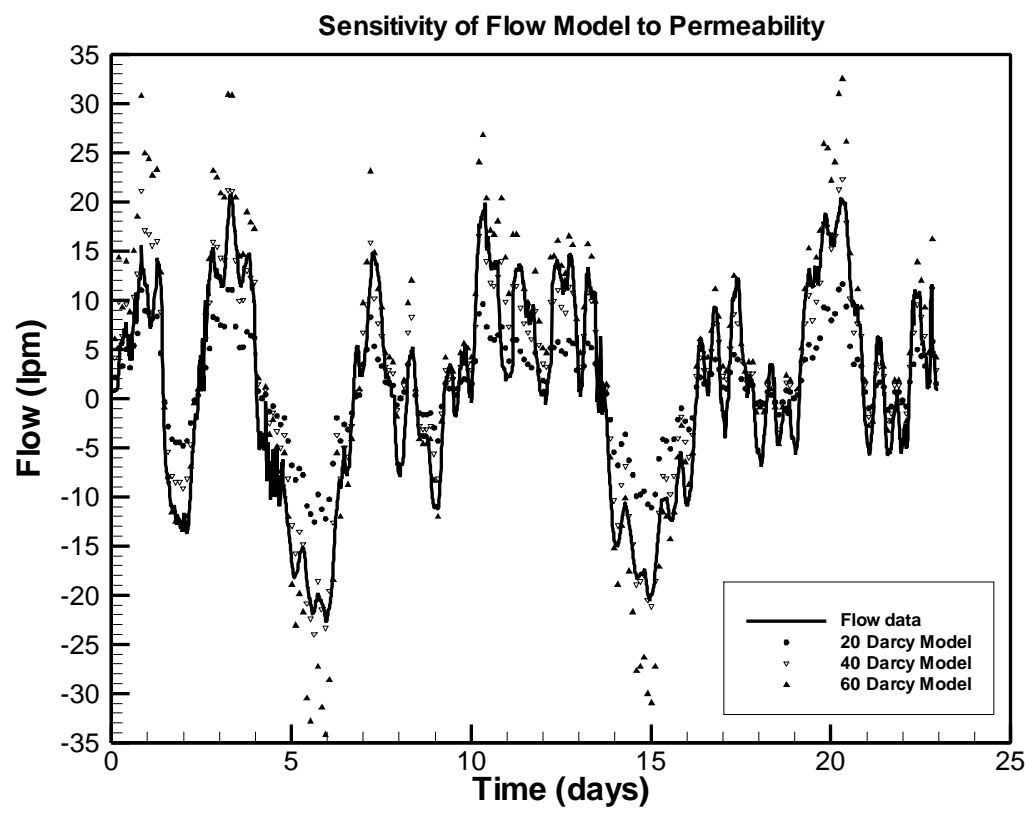

Figure 9. Model response to different permeability values. 